\title{
Cechy somatyczne kobiet zatrudnionych w zakładach chemicznych i odzieżowych górnośląskiego okręgu przemysłowego
}

\author{
Helena Majchrzyk
}

SOMATIC FEATURES IN WOMEN EMPLOYED IN CHEMICAL AND CLOTHING WORKS OF UPPER SILESIAN INDUSTRIAL DISTRICT. Differences in the somatic structure were searched for among women performing different professions. The analysis took into account the age of the examined women.

Rozpatrując dotychczasowe piśmiennictwo dotyczące zróżnicowania budowy ciala niektórych grup zawodowych, wśród publikacji krajowych spotykamy między innymi prace DROZDOWSKIEGO [1967, 1969], MALINOWSKIEGO [1972], SZCZOTKOWEJ [1966], SULAJNISA [1972] i ŚLĘŻYŃSKIEGO [1977]. Wymienieni autorzy koncentrowali swoje badania tylko wokół struktury somatycznej mężczyzn. Nieliczne prace $z$ tego zakresu dotyczą pracujących zawodowo kobiet. Obejmuja one ponadto odmienne przedzialy wieku, jak i dotyczą różnych aspektów tego problemu [KLAUS 1974, KOLASA 1972, KWILECKA 1978, PRYWER 1978, ŚLĘŻYŃSKI 1972, ZENKTELER 1967].

Analiza materialu empirycznego zmierzać będzie zatem do poszukiwania odpo-

Instytut Nauk Biologiczno-Medycznych AWF ul. Mikolowska 72a, 40-065 Katowice wiedzi na pytanie, jak ksztaltują się cechy somatyczne kobiet zatrudnionych bezpośrednio w produkcji, w wybranych zakladach chemicznych $\mathrm{i}$ odzieżowych.

\section{Materiał i metody}

Badaniami przekrojowymi objęto 468 pracownic w wieku produkcyjnym (20-59 lat), zatrudnionych w następujących zakladach: Spóldzielni odzieżowej "Polkon" w Katowicach, Bytomskich Zakladach Odzieżowych w Dąbrowie Górniczej, Zakladach Tworzyw Sztucznych "Erg" w Bieruniu Starym oraz Zakladach Azotowych im. Pawla Findera w Chorzowie. Zarówno wymienione zaklady $z$ terenu górnośląskiego okręgu przemysłowego, 
jak i pracujące w nich kobiety, które poddano pomiarom, zostaly wylosowane za pomocą "liczb żelaznych" [GUILFORD 1964]. W czasie trwania badań wszystkie pracownice byly mieszkankami Śląska.

Spośród 234 pracownic z zakladów odzieżowych, największy odsetek stanowily kobiety zatrudnione na stanowisku szwaczki $(47,9 \%)$, w dalszej kolejności: prasowaczki $(16,2 \%)$, brakarza $(8,5 \%)$ i krawcowej Tabela 1. Staż pracy kobiet z zakładów odzieżowych (o) i chemicznych (ch)

\begin{tabular}{|c|c|c|c|c|c|c|c|c|c|c|c|c|}
\hline \multirow[t]{3}{*}{ Wiek } & \multirow{3}{*}{$\begin{array}{l}\text { Symbol } \\
\text { zespolu }\end{array}$} & \multicolumn{11}{|c|}{ Lata stażu pracy } \\
\hline & & \multicolumn{2}{|c|}{$0-5$} & \multicolumn{2}{|c|}{$6-10$} & \multicolumn{2}{|c|}{$11-15$} & $16-20$ & \multicolumn{2}{|c|}{$21-25$} & 26 i wiec & \multirow{2}{*}{$\sum_{n}$} \\
\hline & & & $\%$ & $n$ & $\%$ & & $\%$ & $n \%$ & & $\%$ & $n \%$ & \\
\hline \multirow[t]{2}{*}{$20-29$} & o & 29 & 40,8 & 33 & 46,5 & 9 & 12,7 & $-\quad$ & - & &. & 71 \\
\hline & ch & 27 & 38,0 & 37 & 52,1 & 7 & 9,9 & $=-$ & - & - & $=-$ & 71 \\
\hline \multirow[t]{2}{*}{$30-39$} & o & 10 & 14,7 & 25 & 36,8 & 26 & 38,2 & 57,4 & 2 & 2,9 & $=-$ & 68 \\
\hline & ch & 3 & 4,4 & 21 & 30,9 & 22 & 32,4 & 2029,4 & 2 & 2,9 & - & 68 \\
\hline \multirow[t]{2}{*}{$40-49$} & a & 2 & 3,0 & 34 & 50,7 & 20 & 29,8 & 23,0 & 6 & 9,0 & 34,5 & 67 \\
\hline & ch & 3 & 4,5 & 15 & 22,4 & 16 & 23,9 & 811,9 & 16 & 23,9 & 913,4 & 67 \\
\hline \multirow[t]{2}{*}{$50-59$} & 0 & 1 & 3,6 & 7 & 25,0 & 8 & 28,6 & 27,1 & & 10,7 & 725,0 & 28 \\
\hline & ch & 1 & 3,6 & 3 & 10,7 & 5 & 17,9 & 517,9 & & 28,5 & 621,4 & 28 \\
\hline
\end{tabular}
$(6.8 \%)$. Znikomy procent obejmowal pozostale specjalizacje zawodowe (lagowacz, ręczniarka, fasoniarka, kompletowacz, guzikarka i szykowacz).

W drugim, porównywanym zespole, obejmującym 234 pracownice $z$ zakładów chemicznych, dostrzegamy największy udzial kobiet na stanowisku suwnicowej $(11,1 \%)$, dalej elaboranta $(8,1 \%)$ i magazyniera $(7,3 \%)$. Pozostala część zatrudnionych w tej branży wykazala duże zróżnicowanie specjalistyczne (laborant, brakarz produkcji, wagowa montażystka, pakowacz karbidu, elektromonter, sprężarkowa, przenośnikowa i sprzątaczka.

Staż pracy badanych kobiet w obydwu grupach zawodowych mieści się $w$ granicach od kilku miesięcy do 32 lat. W najmlodszym zespole staż sięga do 15 lat, w dekadzie 30-39 lat dochodzi już do 25 lat, a wśród starszych i najstarszych kobiet nawet więcej. Należy podkreślić, że największy odsetek pracownic, zarówno z zakladów odzieżowych, jak i chemicznych, mieści się w przedzialach $6-10$ i $11-15$ lat pracy (tab.1).

Zmierzono następujące cechy somatyczne: wysokość ciala $(B-v)$, dlugość tulowia (sst-sy), dlugość kończyny dolnej ( $B-s y)$, szerokość barków $(a-a)$, szerokość mied-

nicy (ic-ic), szerokość klatki piersiowej (thl-thl), glębokość klatki piersiowej (xi-ths), obwody klatki piersiowej i pasa, największe obwody uda i podudzia, faldy skórnotluszczowe (nad mięśniem trójglowym ramienia, poniżej dolnego kąta lopatki i na brzuchu) i masę ciala. Pomiarów antropometrycznych dokonano techniką zalecaną przez Martina i Sallera, poslugując się klasycznym zestawem instrumentów [ĆWIRKO-GODYCKI,

DROZDOWSKI 1972]. Faldy skórno-tluszczowe mierzono faldomierzem o nacisku $10 \mathrm{~g} / \mathrm{mm}^{2}$, zaś masę ciala określano za pomocą wagi lekarskiej, z dokladnością do $0,1 \mathrm{~kg}$.

Ponieważ rozkład wyników grubości podskórnej tkanki tluszczowej jest wyraźnie skośny, dokonano logarytmicznego przeksztalcenia danych pierwotnych. Do przekształcenia stosowano wzór podany przez TANNERA [1963].

$$
Z=100 \log (x-18) \text {, }
$$

gdzie $x$ - pomiar wyrażony w dziesiątych częścıach $\mathrm{mm}$.

Do charakterystyki somatycznej badanych pracownic wykorzystano wskaźniki: tulowiowo-wzrostowy, barkowo-tulowiowy klatki piersiowej, miedniczno-barkowy i smuklości. Zastosowano metodę typolo- 
giczną Milicerowej [KASKA-MIERZEJEWSKA 1976].

Zebrany material poddano opracowaniu statystycznemu [GUILFORD 1964], wyliczając średnią arytmetyczną $(\bar{x})$ oraz standardowe odchylenie $(s)$. Istotność różnic między porównywanymi grupami sprawdzono testem $t$ Studenta dla dużych grup niezależnych [JASICKI, PANEK, SIKORA, STOLYhwo 1962], przy poziomach istotności $\alpha<0,05$. Dokonano ponadto dodatkowych porównań wyodrębnionych grup za pomocą wartości cech unormowanych na średnią arytmetyczną i odchylenie standardowe grupy odniesienia.

Kierując się aktualnym stanem wiedzy o rozwoju fizycznym osób w średnim wieku [WOLAŃSKI 1975], material badawczy podzielono na cztery zespoly dekadowe: kobiet najmlodszych (w wieku 20-29 lat), w średnim wieku (30-39 lat), starszych (40-49 lat) oraz zespól kobiet najstarszych (50-59 lat) (tab. 2). W każdej dekadzie wieku i w obydwu grupach zawodowych do badań zakwalifikowano jednakową liczbę pracownic $w$ tym samym wieku kalendarzowym.

Tabela 2. Liczebnosć i wiek kobiet z zakladów odzieżowych. W grupie z zakładów chemicznych liczebność i średnie wieku identyczne.

\begin{tabular}{c|c|c}
\hline Wiek & $n$ & średnia wieku \\
\hline $20-29$ & 71 & 25,6 \\
$30-39$ & 68 & 34,7 \\
$40-49$ & 67 & 44,8 \\
$50-59$ & 28 & 54,9 \\
\hline
\end{tabular}

\section{Wyniki i dyskusja}

Dane zawarte w tabeli 3 wskazują, że rozpatrywane dwie grupy zawodowe nie wykazują zdecydowanych różnic w obser- wowanych cechach somatycznych. Wśród kobiet najmlodszych (20-29 lat) cechami znamiennie różnicującymi porównywane zbiorowości zawodowe okazaly się: szerokość i glębokość klatki piersiowej, faldy skórno-tluszczowe oraz obwód ramienia. W kolejnej dekadzie, obejmującej pracownice w średnim wieku, zróżnicowanie to wykazaly jedynie glębokość klatki piersiowej oraz wszystkie trzy faldy. Wśród kobiet starszych obserwujemy podobny, jak w przypadku zespolu najmlodszego, zestaw cech somatycznych wskazujących na zróżnicowanie rozpatrywanych grup zawodowych: szerokość i glębokość klatki piersiowej, wszystkie trzy faldy skórno-tluszczowe oraz masa ciala. Nieco odmienny obraz spotykamy w grupie najstarszych pracownic. Tylko w przypadku faldów (biodrowego i ramiennego) oraz szerokości klatki piersiowej różnice okazaly się statystycznie istotne (tab. 3). W wartościach wskaźników nie dostrzegamy również zdecydowanego zróżnicowania porównywanych zespolów zawodowych. Najmlodsze pracownice obu grup różnicuje wskaźnik barkowo-tulowiowy, a starsze - biodrowobarkowy. Ponadto oba te zespoly wiekowe różnicuje wskaźnik smuklości (tab. 3).

Przedstawione wyniki znajdują swoje odzwierciedlenie w profilach obrazujących unormowane wartości cech somatycznych oraz wskaźników budowy ciala pracownic $z$ zakladów odzieżowych na tle pracownic $z$ zakladów chemicznych (rys. 1 i 2 ). Zarówno na profilu dla kobiet najmlodszych, jak i w średnim oraz starszym wieku widać, że jedynie cechy szerokościowe wyraźnie oddalają się w kierunku wartości dodatnich, a pomiary faldów skórno-tluszczowych - ujemnych. Wśród najstarszych pracownic zauważyć można wyraźną tendencję do umiejscowienia się szerokości klatki piersiowej i obwodu ramienia wśród 


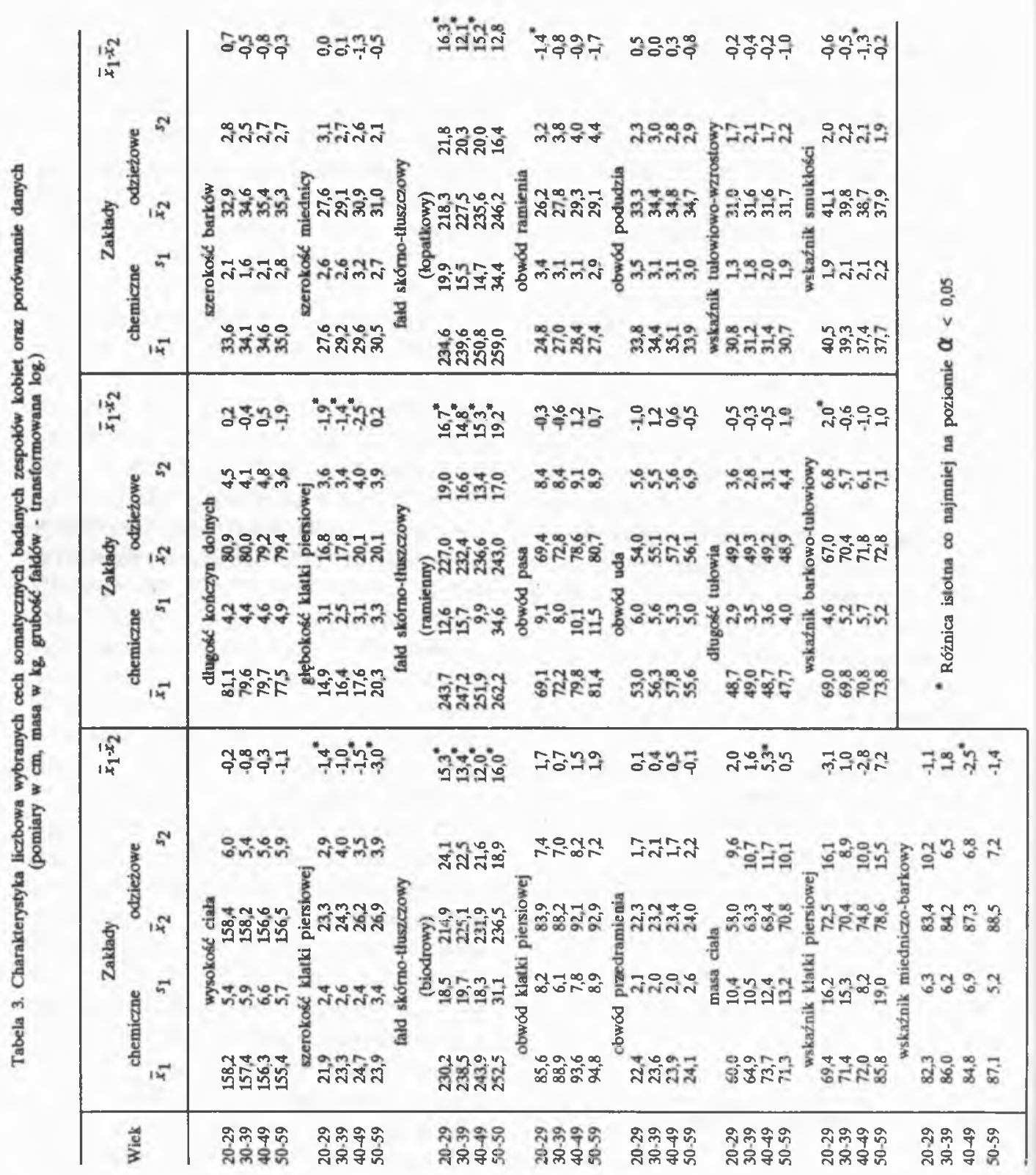




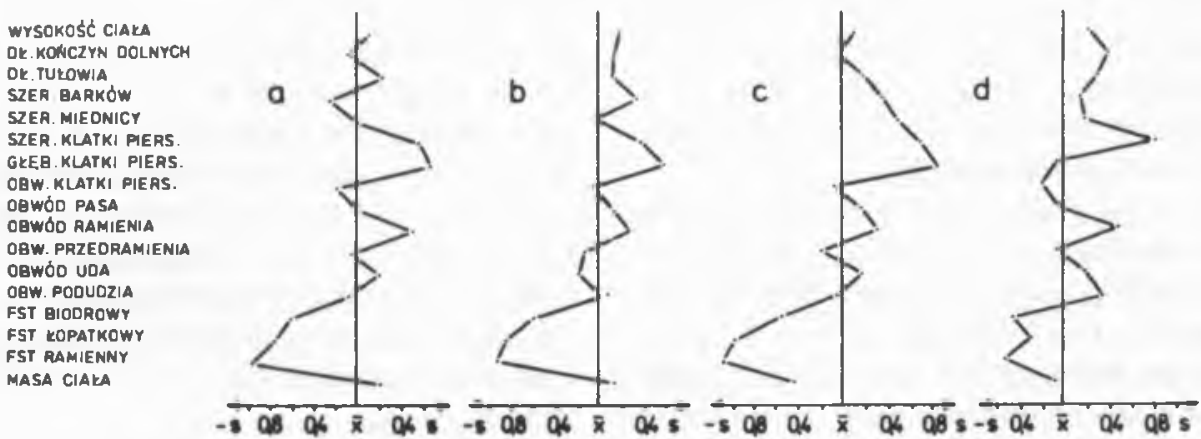

Rys. 1. Profile cech somatycanych pracownic zakladów odzieźowych, w wieku najmlodszym (a), frednim (b), starszym (c) i najstarszym (d), unormowanych na srednią arytmetyaną i odchylenie standardowe zespołów z zakladów chemicznych

WSK. TUkOWIOWO-WZROSTOWY WSK. BARKOWO-TUKOWIOWY WSK. BIODROWO-BARKOWY WSK KLATKI PIERSIOWE WSK. SMUKEOŚCI



a

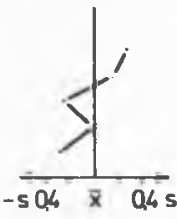

b



C

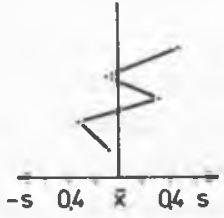

d

Rys. 2. Profile wybranych wskaźników somatycznych pracownic zakładów odzieżowych, w wieku najmlodszym (a), frednim (b), starszym (c) i najstarszym (d), unormowanych na frednią arytmetyczną i odchylenie standardowe zespołów z zakladów chemicznych

WrSOKOSC CIAEA DE. KONCZYN DOUNCH DE. TUkOW/A

SZER. BARKOW

SZER. MIEDNICY SZER.KLATKI PIERS

GREB. KLATKI PIERS OBW. KLATKI PIERS

OBWÓD PASA

OBWÓD RAMIENIA

OQW. PRZEORAMIENIA

CQWÓD UOA

OBW PODUDZIA

FST BIODROWY

FST KOPATKOWY

FST RAMIENNY

MASA CIAEA

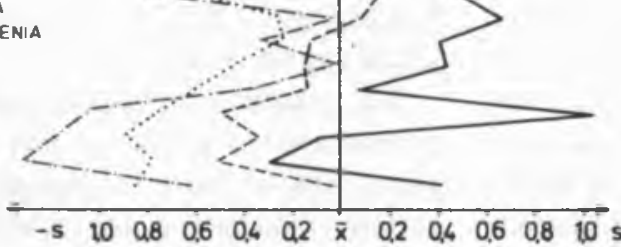

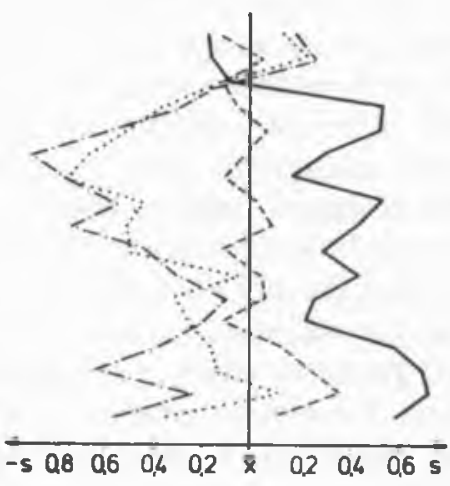

Rys. 3. Profile cech somatycznych pracownic fizycznych z zalładów chemiczmych $\mathrm{i}$ odzieżowych, w wieku najmłodszym (1), średnim (2), starszym (3) i najstarszym (4), unormowanych na śedniq̨ arytmetyczną i odchylenie standardowe ogóhu pracownic umyslowych i fizycanych $(n=800)$. 
wartości dodatnich, zaś, analogicznie jak w poprzednich profilach, faldy skórnotluszczowe skupiają się po stronie wartości ujemnych (rys. 1). Obserwując profile wskaźników budowy ciala dostrzegamy odmienny obraz w poszczególnych zespolach wiekowych (rys. 2).

Kolejną grupę odniesienia dla obydwu porównywanych zespolów zawodowych stanowil ogól pracownic umyslowych i fizycznych z wymienionych na wstępie zakladów produkcyjnych $\mathrm{z}$ tego samego regionu $(n=800)$. Przedstawione profile obydwu grup zawodowych wykazują zbliżony obraz w każdej dekadzie wieku. Zarówno w zespole pracownic z zakładów chemicznych, jak i odzieżowych, unormowane wartosci cech somatycznych grupy najmlodszej lokują się wśród wartości dodatnich. W średnim wieku profil skupia się wokół średniej ogólu badanych kobiet, w dwu najstarszych zespolach (40-49, 50-59 lat) obserwujemy przesunięcie wartości unormowanych w stronę ujemną (rys. 3).

W dalszej ocenie budowy somatycznej badanych pracownic zastosowano metodę Milicerowej

[EASKA-MIERZEJEWSKA 1976], polegającą na klasyfikacji morfologicznej za pomocą "czynników budowy", opartych na wskaźnikach przyrodniczych. Przyjęty podzial uwzględnia cztery czynniki wyrażone cechami dlugościowymi i szerokościowymi oraz zespolem cech określających tęgość budowy i otluszczenie. Wskaźniki przyrodnicze pracownic z zakładów odzieżowych odniesione są w naszym materiale do średniej porównywanej grupy wiekowej $z$ zakladów chemicznych. Nasuwa się pytanie, czy cechy budowy pracownic $\mathrm{z}$ zakladów odzieżowych ukladają się powyżej czy pniżej średnich wartości grupy odniesienia. W najmlodszej i starszej grupie wieku pracownic z zakladów odzieżowych dostrzegamy kod wew- nętrznych proporcji wyrażony wartościami 4-5-3-3. Oznacza to, że grupa wywodząca się z zakladów odzieżowych, w stosunku do porównywanego zespolu z zakladów chemicznych, przy ogólnej wielkości ciala zbliżonej do średniej, odznacza się średnimi dlugościami ciala, nieco większą szerokością oraz malą tęgością i otłuszczeniem. Pozostale grupy wieku charakteryzują się odmiennym kodem wewnętrznych proporcji ciala. W zespole pracownic w średnim wieku kod ma wartość 4-5-4-3, a w najstarszym 4-4-4-3.

Konfrontacja wartości średnich wybranych cech i wskaźników morfologicznych materialu wlasnego $\mathrm{z}$ badaniami KLAUS [1974], w możliwych do porównania dekadach wieku (kobiety starsze i najstarsze), pozwala stwierdzić, że u kobiet z terenu Śląska średnie wartości większości cech somatycznych i wskaźników budowy ciala są zbliżone lub nieco wyższe od wartości populacji szczecińskiej. Charakterystyczny obraz dostrzegamy jednak w przypadku obwodów (klatki piersiowej i uda), masy ciala oraz wskaźnika biodrowobarkowego. Wartości tych cech są wyraźnie wyższe u kobiet ze Śląska. Stwierdzone różnice pomiędzy porównywanymi grupami byly zapewne uwarunkowane wieloma czynnikami, między innymi trendem sekularnym, bowiem odstęp czasu pomiędzy przeprowadzonymi badaniami wynosil kilka lat [KLAUS 1974, KolaSA 1972, ŚLĘŻYŃSKI 1977, WOLAŃSKI 1975, ZENKTELER 1967].

Na zakończenie należy podkreślić, że przedstawiony obraz nie jest $z$ pewnością pelny. Dalsze badania powinny isć w kierunku poglębienia tej problematyki na przykladzie innych grup zawodowych kobiet $\mathrm{z}$ różnych regionów Polski. Wyniki naszych badań nie mogą w pelni ustalić związków 
między zróżnicowaniem cech somatycznych w poszczególnych grupach zawodowych. Zautomatyzowany cykl produkcyjny na stanowiskach pracy w poszczególnych zakladach będzie prawdopodobnie jednym z modulatorów struktury somatycznej robotnic. Praca fizyczna. ksztaltująca pewne stereotypy ruchowe, jak również odsuwanie na plan dalszy pozazawodowej aktywności ruchowej nie pozostają zapewne bez wplywu na procesy inwolucyjne. Przeprowadzony wcześniej sondaż ankietowy [MAJCHRZYK 1982] wykazal ponadto, że wśród badanych grup kobiet tylko nieznaczny odsetek wykazywal istotna aktywność ruchową, która może modelować budowę i wlaściwości funkcjonalne organizmu.

\section{Podsumowanie}

$\mathrm{Z}$ przeprowadzonych badań wynikają następujące wnioski:

1. Analizowane grupy zawodowe w wyodrębnionych grupach wieku nie wykazują istotnych statystycznie różnic w większości obserwowanych cech somatycznych, jak i obliczonych na ich podstawie wskaźników budowy ciala.

2. Zbliżony obraz profilu wybranych cech somatycznych w poszczególnych grupach wieku może wskazywać na podobny przebieg procesu inwolucji $w$ badanych zespolach zawodowych w miarę starzenia się kobiet.

3. Unormowane wartości wskaźników budowy ciala w poszczególnych dekadach wieku wykazują odmienny przebieg profilu.

4. Wszystkie zespoly wiekowe pracownic zzakladów odzieżowych charakteryzują się kodem wewnętrznych proporcii ciala zbliżonym do wartości średniej grupy odnicsienia.

\section{Piśmiennictwo}

CWIRKO-GOIPCKI M., \%. DROZIDOWSKI, 1972 Antropologia w zakresie studisw wycheswania fizycxnego, Warsyawa.

DROZIDOWSKI Z., 1967, Z hadat zrótnirsmania .struktury somarycznej mtodych Francuzdw, Prycgl. Anl rop., 33 57.

DROZDOWSKI Z., 1969, Rumuniscy robotnicy lefni w nypologii Wankego, Przeg. Anirop., 35, 335

GUILFORD J. P., 1964, Podslawerwe metedy statystyrzne w psychologii i pedagogice, Warkzawa

JASICKI B., S. PANIiK, P. SIKORA, E. SIOH.YIIWO 1962, Zarys aneropologii, Warkzawa

K1 AUS E., 1974, Zmiennote rech antropologirznych w procesie starzenia się, Acta Univ. Vratislav., 213, 77

KOIASA E., 1972, Tmiany z wiekiem w budowir somatycznej kobliet miejskich, Mat. i Prace AnIrop., $83,115$.

KWILIECKA M., 1978, Morfologirzne i motoryczne uwarun kowania powodzenia zawodowego przqdrk, Monogr AWF w Poznaniu, nr 97.

P.ASKA-MIS:RTIJI:WSKA T., 1976, \%eszyt do swirzeñ ? antropologii, Wyd. AWF Warkzawa.

MAJCIIRZYK H, 1982, Budowa ciuta a sprawnoste motonyczna kotiet zatrudnisonych w wytranyrh zakta dach chemicznych $i$ odziezowyrh wojewridzlwa kat" wickiego, Praca doktoraka, maszynopia.

MAI.INOWSKI A., 1972, Budowwa somatyr.zna prarownikíw roknych zawndow w Zakladarh Wiskien Szlurznyrh "Silion" w Gonowie Wielkopolshim, Pracg. AnIrop., 37.

PRYWI:H J, 1978, Zmiennote niektonych cech morfologirz nych kobiet $w$ wirku Srednim w ryklu rocznysh obserwacji, Monogr. AWF w Poznaniu, nr 115, 119.

SUIJANIS H., 1972, Podstawy ireningu fizycznego w wojskarh toinirzych, Med. Iot., Warkzawa.

SI.Ę.YNSKKI I., 1972, Charakierystyka budowy i sprawnoste kothiet w wirks 17.39 lat, Roxpraw. Nauk. WSWr' we Wroclawiu, 9,5

SI.ËYYNSSKI I., 1977, Cerhy somatyczne i Iprawnots

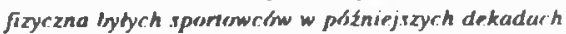
zycia, WSWF w Katowicach.

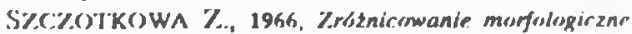
męzczyzn prucujqcych, Mat. i Prace Antrop., 73, 9\%\%

TANNI:R I M., 1963, Rozworj w okressir peskwitania, Warazawa. 
WOLAŃSKI N., 1975, Rozwoj biologiczny czlowieka, Warszawa.

ZENKTELER B., 1967, Rotnice w niektorych cechach somatycznych miedzy kobietami pracujgcymi zawodowo fizycznie a gospodyniami domowymi, Rozpraw. Nauk. WSWF we Wroclawiu, 5, 217.

Maszynopis nadeslano w marcu $1986 \mathrm{r}$.

\section{S u m m a r y}

The analysis of the experimental material aimed at giving the answer to the question, what were the trends of shaping somatic features in women representing the two professional groups employed in the area of the Upper Silesian Industrial District.

The study was carried on 468 work-women in the productive ages ( 20 - 59 years) employed in chosen chemical and clothing works of Katowice Province. The experimental material was divided into four decade-groups, joining the women in pairs according to their calendar age. 17 somatic features were measured and on their basis five indices of body structure were estimated. The results of the analysis has shown that both compared professional groups, over the whole period of the observation, do not present any clear differentiation in all the somatic features and the indices of body structure estimated on their basis. 